\title{
Adverse Childhood Experiences of Urban and Rural Preschool Children in Poverty
}

\author{
Leanne Whiteside-Mansell ${ }^{1, *}$, Lorraine McKelvey ${ }^{1}$, Jennifer Saccente ${ }^{2}$ and James P. Selig ${ }^{3}$ \\ 1 Department of Family and Preventive Medicine, University of Arkansas for Medical Sciences, Little Rock, \\ AR 72205, USA \\ 2 College of Medicine, University of Arkansas for Medical Sciences, Little Rock, AR 72205, USA \\ 3 Department of Biostatistics, University of Arkansas for Medical Sciences, Little Rock, AR 72205, USA \\ * Correspondence: WhitesideMansellLeanne@uams.edu; Tel.: +1-870-236-0997
}

Received: 18 June 2019; Accepted: 20 July 2019; Published: 23 July 2019

\begin{abstract}
Adverse childhood experiences (ACEs) have long-term health consequences. Young children in the southern part of the United States (US) are at greater risk than children in other parts of the US. This study assessed preschool children ACEs using a family-friendly tool, the Family Map (FMI), and compared children living in rural/urban areas while examining the potential moderation of race. The FMI-ACE score was examined as a total and two sub-scores. We found that race did not moderate the FMI-ACE score but that Black children (Cohen's $d=0.52$ ) and children in urban and large rural areas were at highest risk (Cohen's $d=0.38$ ). However, the subscale FMI-ACEs parenting risk was moderated by race such as that Black children were less at risk in rural areas than urban (Cohen's $\mathrm{d}=0.62$ ). For FMI-ACEs environmental risk, race moderated risk such that Black children were most at risk in large rural areas but less so in small rural areas (Cohen's $d=0.21$ ). Hispanic children were most at risk in small rural areas and least in large rural environments. Findings from this study suggest that targeting the most at-risk children for interventions should consider the context including race and location.
\end{abstract}

Keywords: rural health; adverse childhood consequences; poverty; preschool children

\section{Introduction}

Children living in rural communities in the United States (US) are at greater risk than children in urban areas for an array of health and developmental conditions including obesity and unintended injury [1,2]. Some of the contributors to these serious health conditions experienced by rural children are known. For example, many children in rural America live in poverty and children living in poverty are more likely to have developmental concerns [2-5]. Rural parents more often have less education and less access to consistent full-time employment than urban parents-both linked to health outcomes [6]. While the challenges experienced by those in rural areas are far from homogeneous, remoteness is a factor in access to health services, including preventive healthcare services and trained health and education staff $[3,7]$.

However, research on the environmental experiences of children has led to a new contributor to health inequities, adverse childhood experiences (ACEs). ACEs are traumatic events experienced before the age of 18 years. While studies have used different measures of ACEs, constructs typically assessed include the direct experiences of maltreatment (physical, sexual, or emotional abuse and/or physical or emotional neglect) and family and parent characteristics [8]. The latter are associated with family stress or correlates of maltreatment, such as instability and disruptions in the family (incarceration of a family member, domestic violence, parental separation/divorce) or characteristic of a parent (mental illness, substance abuse). The 1998 seminal study by Felitti and colleagues linked 
these 10 indicators of ACEs (Kaiser-ACEs) with adult health consequences [9]. Their study provided the rationale for the 10 adverse events and has guided subsequent research. In the intervening years, a range of studies confirmed and extended the evidence of negative physical and psychological consequences [10]. Combined, these studies document that experiencing even one adversity increases the risk of negative outcomes [11-15].

Recent national estimates indicate that as many as $60 \%$ of adults in the US experienced at least one ACE as children [16]. A key finding by Felitti and colleagues is a consistent linear (dose-response from zero to 10) relationship between the number of adverse events experienced and the likelihood of negative consequences. About $25 \%$ of adults are thought to have experienced three or more ACES and 9\% report five or more [16]. There are many examples of the cumulative effect of ACES on developmental outcomes. For example, compared to adults with no ACEs, those with five or more ACEs had a 2.6 times greater risk of chronic obstructive pulmonary disease (COPD) [17]. This cumulative effect of the number of ACEs has been shown repeatedly across a wide range of physical and mental health outcomes [18].

While the percentage of the general population experiencing at least one ACE is high, nearly all of the studies are retrospective in adult populations. The most nationally representative data on ACEs in the lives of children (not adults retrospectively reporting about their childhood) comes from the National Survey of Children's Health (NSCH) [2]. However, this study is limited because of differences in the assessment of ACEs from the assessment of ACEs in the original Kaiser study. The NSCH-ACEs measure does not assess indicators of child maltreatment. This may be because asking parents directly about abuse and neglect is problematic. The NSCH-ACEs measure included household dysfunction indicators similar to the Kaiser-ACEs studies. The NSCH-ACEs included measures of parental death, racial discrimination, witnessing neighborhood violence, and family economic hardship in the cumulative ACE score. While there is a rationale for these shifts in definition, it makes an investigation of differences by race and location (e.g., urban, rural) difficult.

The NSCH documented differences by geographic area, with $53 \%$ of children (birth to 18 years) living in small rural areas having had at least one ACE (as defined by NSCH), compared to $47 \%$ of children living in urban areas [2]. The NSCH suggested that the disparity of risks begins early. In $\mathrm{NSCH}$, among children between birth and 5 years, $41 \%$ of rural children compared to $35 \%$ of children in urban areas had already experienced one ACE. Still, the geographic pattern is not that simple. The NSCH defined three geographic areas: urban, large rural (populations of 10,000 to 49,999), and small rural (populations of 2500 to 9999 persons and their surrounding areas) [1]. Across children of all ages, more living in large rural areas ( $45 \%$ for children birth to 5 ) experienced at least once ACE compared to children in the other two geographic areas.

Although the NSCH-ACE indicator is confounded by poverty status and racial discrimination, other studies also suggest the prevalence of ACEs differs by geographic area and/or racial groups $[3,19]$. In general, rural and southern states have higher rates than more urban and coastal states [20,21]. Racial differences in ACE exposure have been documented in multiple studies including adults and children, such as the NSCH. In the original ACEs study by Felitti and colleagues, participants who identified as Black, Hispanic, or "other" reported higher exposure to two, three, or four ACEs compared to white participants [9]. Focusing specifically on abuse, in a recent cohort study of 5502 participants, Black women reported higher rates of physical abuse in their childhoods than white women, whereas white women reported more emotional abuse in their childhoods than Black women. The results were slightly different for men, with white men reporting higher rates of emotional and sexual abuse and Black men reporting more physical abuse [22].

There is evidence that ACEs representing family instability, such as parental separation, domestic violence, and incarceration of a household member, vary along racial and geographic lines. Parental separation/divorce is the most common ACE and is known to be associated with poorer academic outcomes and interpersonal skills for children during the period of the divorce [23,24]. A recent study of the NSCH data found that US-born Hispanic children are more likely to experience parental 
separation/divorce than white, Black or immigrant Hispanic children [25]. Black and Hispanic children are more likely to be exposed to parental incarceration and domestic violence between parents compared to white children $[25,26]$. In the context of geographic setting, a cross-sectional analysis of children in South Carolina found slightly reduced rates of parental separation, domestic violence, and incarceration of a household member among rural participants [23]. Overall, minority children experience parental separation, domestic violence, and household incarceration more often than white children do. Domestic violence is more frequent in rural areas [27,28].

Other ACE indicators that threaten the optimal development of children within the household differ by race and geographic location. For example, there are racial and geographic disparities in substance abuse and mental illness. While illicit drug use and alcohol abuse are reported at approximately equal rates among urban and rural residents ages 12 and up, the risk for many mental illnesses, such as mood, psychotic, and anxiety disorders, is higher in cities $[29,30]$. For example, the risk of schizophrenia shows a dose-response relationship with time spent in a city during childhood [30]. When examined in the context of race, Hispanic, Black, and white children of US-born parents are approximately equally likely to have a household member with mental illness [25]. However, Hispanic children are more likely than white children to be exposed to household drug or alcohol abuse, putting them at increased risk of other ACEs such as abuse or neglect [25].

The assessment of current childhood adversity and the ability to examine links is a serious gap in the current research foundation. The research findings to-date are lacking in several areas. As mentioned, the NSCH survey's modified assessment of ACEs excluded indicators of childhood abuse and neglect. Examining this distribution is key to developing effective interventions to prevent the negative physical and psychological outcomes associated with ACE exposure [9,31]. Further, NSCH used poverty and the experience of racial discrimination as indicators of adverse experiences of children. This may be related to the conflictual findings between children and adults in the prevalence of rural-urban ACES. That is, while the NSCH suggests that children living in rural locations are more at risk; studies of adults suggest that adults in urban areas report a higher history of risk from childhood experiences [23,32]. While these changes to the definition of an ACE indicator may be justified, it makes it difficult to understand the different experiences of children as defined by Felitti and colleagues [9]. This inclusion makes the task of researchers and policy-makers focused on the levels of risk within the population of children living in poverty more difficult.

Our study expanded on the 2012 portrait of rural children's experiences described by the National Survey of Children's Health (NSCH) by focusing on a large sample of children living in poverty in a Southern state [33]. We focused on a sample of preschool children enrolled in early childhood education (ECE) programs (both center- and home-based programs) serving low-income families. The sample was diverse in race and geographic location. We used location designations similar to the NSCH. We used a definition of childhood adversity that was constructed to align with the Kaiser-ACEs while assessing the experiences of preschool children [15]. The validated survey tool was developed to support family engagement in ECE programs serving children ages 3 to 5 years [34].

Analyses to date have documented race/ethnicity and geographic location as risk indicators but not the potential moderation of one on the other. In this study, we examined the combination of race and geographic location, both of which are linked to adversity for children and families. In all, our study was the first to examine ACEs for children specifically in the preschool years while examining the interaction of race and geographic location on adversity exposures.

\section{Materials and Methods}

\subsection{Participants}

Participants $(\mathrm{N}=3911)$ were parents with preschool-aged children receiving early childhood services in Arkansas. Participants were a convenience sample of parents and/or children enrolled in programs serving low-income families. Programs served children from 3- to 5-years-of-age 
in center-based childhood education or home-based parenting education programs. Six Head Start agencies provided data from 2028 families [35]. Head Start programs served children with income not exceeding $100 \%$ of poverty or other at-risk criteria (children in foster care or with developmental delay/disability) [35]. Four state-funded pre-Kindergarten programs provided data from 554 participants. State-funded programs served children with income not exceeding 200\% of poverty or other at-risk criteria (adolescent parent, limited English proficiency, parent history of substance addiction or abuse/neglect) [36]. Fifteen Home Instruction for Parents of Preschool Youngsters (HIPPY) home visiting programs provided data for 1309 families. HIPPY's goal is to promote school readiness with age-appropriate parent teaching in the home. Families were eligible for HIPPY based on demographic characteristics (low-income or a single and/or teen parent), parent characteristics (such as parental history of abuse, incarceration, military deployment, disability, or chronic illness), and child characteristics (developmental delay, pre-term/low birth-weight, disability, or chronic illness) [15]. The Institutional Review Board of the University of Arkansas for Medical Sciences approved the study (Protocol \#133672).

\subsection{Procedures}

Data for this study focused on the Family Map interview (FMI) conducted by program staff during enrollment or soon after. Data were extracted from program records and scanned into an electronic system. Children's race and ethnicity were reported by caregivers during the interview. Participants with missing information for race/ethnicity that were not from one of the target races (i.e., white or Black) or ethnicity codes (i.e., Hispanic) were excluded ( $n=239 ; n=132$ : Head Start; $\mathrm{n}=33$ : State-funded; $\mathrm{n}=74$ : Home Visiting). Further, 20 participants from one Head Start agency were excluded because their location code was missing. The resulting analyses data set included 3652 participants.

Over 180 trained program staff interviewed the primary caregiver (e.g., parent) using The Family Map Inventory-Early Childhood (FMI-EC) [34,37]. All program staff conducting interviews received 6 hours of training. On-site support in the administration of the interview was provided as needed by the research team. Most caregivers interviewed were the biological mother $(86.4 \%)$ or father $(5.7 \%)$. Other caregivers interviewed were the child's grandmother $(4.2 \%)$, a step or adoptive parent $(1.9 \%)$, other relative $(0.4 \%)$, or other adult (foster parent, $0.7 \%$, unknown, $0.7 \%$ ). Interviews were collected within the first 3 months of the child's enrollment in the program. Data were extracted in cohorts over multiple years such that no child could be represented more than once (from 2014 to 2016). The county of the agency was coded for each family and linked to 2013 Rural-Urban Continuum Codes to classify the community by population size and location to another metro area with up to nine codes [38].

\subsection{Instruments}

The Family Map Inventories (FMIs) were designed for use by early childhood staff (e.g., ECE/parent educators), the FMIs consist of semi-structured interviews and observation items to assess family and home environment characteristics associated with children's well-being. There are three versions of FMI based on the child's age (i.e., prenatal, under 3 years, and 3-5 years) each in English and Spanish [34,37]. This study used the FMI for Early Childhood (FMI-EC, for children 3-5 years-of-age). Using FMI, program staff systemically evaluate risk factors (e.g., parental mental illness, harsh parenting style, food insecurity) and areas of strength (e.g., safe home environment, available learning materials) in families with young children. Beyond identifying service needs, the goal of the FMI is also to support strong parent-teacher partnerships and effective interventions.

FMI-EC interviews take approximately one hour and consist of 12 domains in three areas: (a) child physical and social experiences; (b) family climate; and (c) parent characteristics. Previous research describes the rationale for each of the 12 constructs, all of which play key roles in healthy child development [34,37]. The FMIs have been shown to have sufficient internal consistency reliability across domains (Cronbach's alpha range $=0.68-0.90$ ) and test-retest reliability of concordance of 
risk identification (63-100\%) [34,37]. Risks are defined by research-based guidelines (e.g., American Academy of Pediatrics). The FMIs and other national studies find similar rates of family risks in low-income populations [34,37,39,40]. The FMIs have been successfully implemented in home visiting programs, early childhood education programs, including Early Head Start, Head Start, and schooland community-based programs [37].

Adverse Childhood Experiences (FMI-ACEs). Specific FMI-EC items (see Table 2) have been shown to be close correlates for the retrospectively-reported Kaiser-ACEs [9,15,31]. Paralleling the Kaiser-ACEs, documentation of any risks within a construct represented a positive screening. However, rather than providing a comprehensive history of risk exposure, FMI-ACEs screens the child's current environment, permitting the ability to provide appropriate referrals and supports as well as documenting change in risk over time [15]. This method of screening for ACEs has been shown to accurately predict child-maltreatment risk [15].

In this study, we examined the total FMI-ACEs score and two sub-scores. The first sub-score represented risks associated with parenting and was composed of the first five risk areas as seen in Table 2 (FMI-ACEs Parenting). The second sub-score represented risks associated with the family and home environment and combined the second set of five items in Table 2 (FMI-ACEs Family). These sub-scores were not used by McKelvey et al.; however, they were consistent with our intent to create and investigate a construct similar to the one used in the NSCH study (i.e., environmental threats) and examine FMI-ACEs Parenting risk separately [15]. Further, a range of research has supported the clustering of ACEs [14,41].

\subsection{Approach to Analysis}

Preliminary analyses examined distributional assumptions and bivariate comparisons of demographic characteristics using $\chi^{2}$ tests. Comparisons were conducted (SPSS Version 23.0; IBM, 2015) [38] using ANOVA or logistic regression with main effects and interaction terms (Table 1). ANOVA or logistic regression with post hoc Bonferroni-corrected tests using the Holm-Bonferroni method, which is more powerful than Bonferroni-corrected tests [42,43]. ANOVA was used with caregiver age (in years), caregiver employment (in hours/week), number of adults living in the home, and number of children living in the home. Logistics regression was used to examine differences in child gender, child age (over 54 months), who was interviewed (biological mother vs other), partner in the home, and caregiver education completed (more than high school degree vs less). Holm-Bonferroni-corrected tests examined interactions based on nine tests. When interaction terms were not significant, main effects were examined.

Full Information Maximum Likelihood (FIML) was used to estimate regression models predicting the ACE scores [44,45]. FIML uses all available data and provides the least biased estimates in multiple regression models with missing data compared to other commonly used methods such as pairwise or listwise deletion [46]. FIML estimates were computed using SAS (9.4) [47]. Demographics were included as covariates in multivariate analyses. These included child characteristics (child gender) and family/parent characteristics (parent age, education, employment status, number of children in the home). The results of the FIML tests are shown in Table 2. 
Table 1. Comparisons of characteristics across location and race/ethnicity of participants.

\begin{tabular}{|c|c|c|c|c|c|c|c|c|c|c|}
\hline & \multicolumn{3}{|c|}{ Urban } & \multicolumn{3}{|c|}{ Large Rural } & \multicolumn{3}{|c|}{ Rural } & \multirow[b]{2}{*}{ Total } \\
\hline & White & Black & Hispanic & White & Black & Hispanic & White & Black & Hispanic & \\
\hline $\mathrm{N}$ & 620 & 1377 & 402 & 125 & 146 & 39 & 751 & 62 & 130 & 3652 \\
\hline Percent & $17.0 \%$ & $37.7 \%$ & $11.0 \%$ & $3.4 \%$ & $4.0 \%$ & $1.1 \%$ & $20.6 \%$ & $1.7 \%$ & $3.6 \%$ & $100 \%$ \\
\hline Child Male ${ }^{b}$ & $46.6 \%$ & $48.7 \%$ & $50.9 \%$ & $52.9 \%$ & $52.7 \%$ & $47.2 \%$ & $54.1 \%$ & $44.8 \%$ & $54.3 \%$ & $50.2 \%$ \\
\hline \multicolumn{11}{|l|}{ Child Age ${ }^{b}$} \\
\hline 42 months or less & $26.9 \%$ & $29.6 \%$ & $27.8 \%$ & $34.7 \%$ & $35.3 \%$ & $43.2 \%$ & $33.1 \%$ & $21.1 \%$ & $26.6 \%$ & $30.0 \%$ \\
\hline 43-54 months & $46.8 \%$ & $46.7 \%$ & $44.8 \%$ & $45.2 \%$ & $39.7 \%$ & $37.8 \%$ & $44.4 \%$ & $43.9 \%$ & $48.4 \%$ & $45.6 \%$ \\
\hline$>54$ months & $26.3 \%$ & $23.7 \%$ & $27.5 \%$ & $20.2 \%$ & $25.0 \%$ & $18.9 \%$ & $22.5 \%$ & $35.1 \%$ & $25.0 \%$ & $24.4 \%$ \\
\hline \multicolumn{11}{|l|}{ Caregiver Interviewed } \\
\hline Biological Mother $b$ & $78.3 \%$ & $81.7 \%$ & $82.3 \%$ & $84.8 \%$ & $80.4 \%$ & $94.9 \%$ & $84.5 \%$ & $82.3 \%$ & $82.9 \%$ & $82.0 \%$ \\
\hline Biological Father & $6.9 \%$ & $4.8 \%$ & $7.1 \%$ & $5.6 \%$ & $2.8 \%$ & $2.6 \%$ & $4.4 \%$ & $4.8 \%$ & $10.1 \%$ & $5.4 \%$ \\
\hline Other & $14.9 \%$ & $13.5 \%$ & $10.6 \%$ & $9.6 \%$ & $16.8 \%$ & $2.6 \%$ & $11.0 \%$ & $12.9 \%$ & $7.0 \%$ & $12.5 \%$ \\
\hline Partner in Home ${ }^{* *, b, d}$ & $70.8 \%$ & $40.2 \%$ & $72.9 \%$ & $60.0 \%$ & $41.1 \%$ & $59.0 \%$ & $76.4 \%$ & $46.8 \%$ & $76.2 \%$ & $58.7 \%$ \\
\hline \multicolumn{11}{|l|}{ Caregiver Age $^{a}$} \\
\hline 24 years or less & $22.3 \%$ & $21.7 \%$ & $16.8 \%$ & $24.5 \%$ & $22.7 \%$ & $28.1 \%$ & $19.5 \%$ & $27.1 \%$ & $17.2 \%$ & $20.9 \%$ \\
\hline $25-34$ years & $52.6 \%$ & $58.8 \%$ & $56.4 \%$ & $55.9 \%$ & $57.6 \%$ & $62.5 \%$ & $58.5 \%$ & $52.5 \%$ & $51.7 \%$ & $56.9 \%$ \\
\hline 35 or older & $25.1 \%$ & $19.4 \%$ & $26.7 \%$ & $19.6 \%$ & $19.7 \%$ & $9.4 \%$ & $22.0 \%$ & $20.3 \%$ & $31.0 \%$ & $22.1 \%$ \\
\hline \multicolumn{11}{|l|}{ Employment $*, \mathrm{a}, \mathrm{d}$} \\
\hline Not Working & $47.8 \%$ & $31.9 \%$ & $42.6 \%$ & $43.0 \%$ & $35.6 \%$ & $28.1 \%$ & $40.3 \%$ & $30.5 \%$ & $47.4 \%$ & $38.6 \%$ \\
\hline 20 hours or less & $10.4 \%$ & $9.7 \%$ & $13.1 \%$ & $15.0 \%$ & $6.7 \%$ & $9.4 \%$ & $10.4 \%$ & $10.2 \%$ & $12.1 \%$ & $10.5 \%$ \\
\hline$>20$ hours & $41.8 \%$ & $58.4 \%$ & $44.2 \%$ & $42.0 \%$ & $57.8 \%$ & $62.5 \%$ & $49.3 \%$ & $59.3 \%$ & $40.5 \%$ & $51.0 \%$ \\
\hline \multicolumn{11}{|l|}{ Education $*, b, c$} \\
\hline No Degree & $11.2 \%$ & $8.1 \%$ & $46.0 \%$ & $20.4 \%$ & $8.2 \%$ & $37.0 \%$ & $5.5 \%$ & $10.2 \%$ & $43.1 \%$ & $14.2 \%$ \\
\hline High School Degree & $54.4 \%$ & $54.5 \%$ & $45.2 \%$ & $49.0 \%$ & $50.8 \%$ & $44.4 \%$ & $45.1 \%$ & $62.7 \%$ & $39.7 \%$ & $50.7 \%$ \\
\hline Some College & $34.4 \%$ & $37.4 \%$ & $8.9 \%$ & $30.6 \%$ & $41.0 \%$ & $18.5 \%$ & $49.4 \%$ & $27.1 \%$ & $17.2 \%$ & $35.1 \%$ \\
\hline \multicolumn{11}{|l|}{ Adults in Household $* * a, e, d$} \\
\hline Mean & 1.17 & 0.90 & 1.42 & 1.09 & 1.06 & 0.79 & 1.04 & 0.93 & 1.06 & 1.11 \\
\hline $\mathrm{SD}$ & 0.89 & 0.85 & 1.00 & .81 & 0.95 & 0.74 & 0.88 & 0.77 & 0.70 & 0.88 \\
\hline \multicolumn{11}{|l|}{$\underset{* *, a, c}{\text { Children in Household }}$} \\
\hline Mean & 1.61 & 1.66 & 1.77 & 1.45 & 1.49 & 1.70 & 1.38 & 1.38 & 1.78 & 1.50 \\
\hline SD & 1.23 & 1.36 & 1.25 & 1.18 & 1.45 & .99 & 1.08 & 1.32 & 1.33 & 1.17 \\
\hline
\end{tabular}

${ }^{*} p<0.05,{ }^{* *} p<0.01$ with $^{\mathrm{a}}$ ANOVA or ${ }^{\mathrm{b}}$ Logistic Regression including main effects and interaction terms (race by geographic area) followed by Holm-Bonferroni method corrections for number of tests. ${ }^{c}$ Significant interactions; ${ }^{\mathrm{d}}$ Significant main effects race, e Significant main effects location. 
Table 2. Adverse childhood experiences from family map inventories with unadjusted percent and means.

\begin{tabular}{|c|c|c|c|c|c|c|c|c|}
\hline \multirow{2}{*}{$\begin{array}{c}\text { Original Ace } \\
\text { Construct }\end{array}$} & \multirow{2}{*}{$\begin{array}{c}\text { Family Map Item } \\
\text { Description }\end{array}$} & \multicolumn{3}{|c|}{ Race/Ethnicity } & \multicolumn{3}{|c|}{ Geographic Location } & \multirow[t]{2}{*}{ Total } \\
\hline & & White & Black & Hispanic & Urban & Large Rural & Rural & \\
\hline FMI-ACEs-Parenting Subscore ${ }^{a}$ & Mean (item 1-5) & 0.64 & 0.88 & 0.60 & 0.81 & 0.74 & 0.55 & 0.74 \\
\hline & $\begin{array}{l}\text { SD } \\
\text { Family Members Verbal Anger/Discinline }\end{array}$ & 0.87 & 0.94 & 0.86 & 0.93 & 0.83 & 0.84 & 0.91 \\
\hline $\begin{array}{l}\text { 1. Emotional Abuse } \\
\text { 2. Physical Abuse }\end{array}$ & & $5 \%$ & $\begin{array}{r}8 \% \\
33 \%\end{array}$ & $5 \%$ & $7 \%$ & $4 \%$ & $\begin{array}{r}5 \% \\
18 \%\end{array}$ & $6 \%$ \\
\hline 2. Physical Abuse & Exposure to Violence or Physical Discipline & $19 \%$ & $33 \%$ & $13 \%$ & $26 \%$ & $26 \%$ & $18 \%$ & $24 \%$ \\
\hline 3. Sexual Abuse & $\begin{array}{l}\text { Child Exposed to Sexual or Open Child } \\
\text { Protective Services }\end{array}$ & $6 \%$ & $4 \%$ & $2 \%$ & $5 \%$ & $4 \%$ & $5 \%$ & $5 \%$ \\
\hline 4. Emotional Neglect & Family Members Not Cohesive & $12 \%$ & $22 \%$ & $18 \%$ & $21 \%$ & $15 \%$ & $8 \%$ & $17 \%$ \\
\hline 5. Physical Neglect & Food Insecurity, Homeless or Crowded Home & $22 \%$ & $20 \%$ & $21 \%$ & $22 \%$ & $21 \%$ & $19 \%$ & $21 \%$ \\
\hline FMI-ACEs-Family Subscore ${ }^{\mathrm{a}, * *}$ & $\begin{array}{l}\text { Mean (item 6-10) } \\
\text { SD }\end{array}$ & $\begin{array}{l}0.59 \\
0.82\end{array}$ & $\begin{array}{l}0.76 \\
0.81\end{array}$ & $\begin{array}{l}0.41 \\
0.72\end{array}$ & $\begin{array}{l}0.68 \\
0.82\end{array}$ & $\begin{array}{l}0.75 \\
0.85\end{array}$ & $\begin{array}{l}0.49 \\
0.76\end{array}$ & $\begin{array}{l}0.63 \\
0.81\end{array}$ \\
\hline 6. Parental Separation or Divorce & $\begin{array}{l}\text { Parent Living Outside the Home and/or } \\
\text { Owed Child Support }\end{array}$ & $32 \%$ & $51 \%$ & $23 \%$ & $42 \%$ & $49 \%$ & $27 \%$ & $39 \%$ \\
\hline 7. Mother Treated Violently & Someone in Home Hurt & $6 \%$ & $6 \%$ & $4 \%$ & $7 \%$ & $7 \%$ & $3 \%$ & $6 \%$ \\
\hline 8. Household Substance Abuse & Friends/Family with Drinking/Drug & $2 \%$ & $2 \%$ & $3 \%$ & $2 \%$ & $1 \%$ & $2 \%$ & $2 \%$ \\
\hline 9. Household Mental Illness & Depression Screen & $10 \%$ & $7 \%$ & $7 \%$ & $8 \%$ & $7 \%$ & $9 \%$ & $8 \%$ \\
\hline $\begin{array}{l}\text { 10. Incarcerated Household } \\
\text { Member }\end{array}$ & Family Involved w/Legal System & $11 \%$ & $9 \%$ & $4 \%$ & $9 \%$ & $10 \%$ & $8 \%$ & $9 \%$ \\
\hline FMI-ACEs-Total Score ${ }^{\text {a }}$ & $\begin{array}{l}\text { Mean (items 1-10) } \\
\text { SD }\end{array}$ & $\begin{array}{l}1.25 \\
1.38\end{array}$ & $\begin{array}{r}1.63 \\
* * \\
1.43\end{array}$ & $\begin{array}{l}1.01 \\
1.34\end{array}$ & $\begin{array}{l}1.50 \\
1.45\end{array}$ & $\begin{array}{l}1.47 \\
1.33\end{array}$ & $\begin{array}{r}1.05^{* *} \\
1.30\end{array}$ & $\begin{array}{l}1.38 \\
1.42\end{array}$ \\
\hline Number of Aces & & & & & & & & \\
\hline 0 & & $38.3 \%$ & $23.3 \%$ & $47.6 \%$ & $29.4 \%$ & $28.1 \%$ & $44.6 \%$ & $33.3 \%$ \\
\hline 1 & & $27.8 \%$ & $30.2 \%$ & $26.3 \%$ & $28.7 \%$ & $27.0 \%$ & $28.8 \%$ & $28.6 \%$ \\
\hline 2 & & $17.0 \%$ & $23.7 \%$ & $14.5 \%$ & $21.0 \%$ & $26.7 \%$ & $13.5 \%$ & $19.5 \%$ \\
\hline 3 & & $9.1 \%$ & $12.5 \%$ & $6.2 \%$ & $11.1 \%$ & $10.4 \%$ & $7.5 \%$ & $10.1 \%$ \\
\hline $4+$ & & $7.8 \%$ & $10.4 \%$ & $5.5 \%$ & $9.7 \%$ & $7.8 \%$ & $5.7 \%$ & $8.5 \%$ \\
\hline
\end{tabular}

${ }^{* *} p<0.01$ a Comparisons controlled for child (age, gender), parent (age, education, work status), and family (number of children in home) characteristics and adjusted for missing data with FMIL; however values in table are unadjusted. 


\section{Results}

\subsection{Preliminary Analysis of Racial and Geographic Description of Sample}

Children $(n=3652)$ represented counties from eight of the nine metro and non-metro categories. Category definition was based on the definition from the Office of Management and Budget. In this study, we combined areas into three similar to the NSCH study. The majority of children (65.7\%) were in metro areas considered urban. Urban area definition was based on population and worker commuting criteria from census data and includes counties with more than 250,000 people but can contain less. Of the children in non-metro areas, $8.5 \%$ were in large rural areas. These areas are counties of populations of 10,000 to 49,999 persons and their surrounding areas. Finally, 25.8\% of children were in smaller rural areas. These areas were small towns with populations of 2500 to 9999 persons and their surrounding areas.

Families were not distributed evenly by race across geographic areas. More Black families lived in urban areas compared to other areas (86.9\% in urban, 9.2\% in large rural, and 3.9\% in small rural, $\left(\chi^{2}(4, N=3652)=888.04, p<0.001\right)$. The distribution for white and Hispanic families was more equal with the exception of large rural (white: 41.45, 8.4\%, 50.2\%; Hispanic: 70.4\%, 6.8\%, 22.8\%, for urban, large rural, and small rural respectively). Immigration status and country of origin were not available for participants; however, based on parent report, more Hispanic parents were comfortable communicating in English in large rural areas (82\% compared to $48 \%$ ) than those in urban or small rural area $\left(\chi^{2}(2, N=615)=16.08, p<0.001\right)$.

An examination of demographic characteristics across location and race/ethnicity of participants is shown in Table 1. Two significant interactions (race by location) were identified: number of children in the home $(\mathrm{F}(4,3230)=4.89, p<0.001)$ and caregiver education levels (Wald $\chi^{2}(4, N=3300)=16.39$, $p<0.003)$. Black families in small rural areas had fewer children than families of other races/ethnicities in small rural areas and fewer than Black families in urban or large rural areas. On the other hand, Hispanic families in urban areas had more children than other Hispanic families and other urban families. White caregivers in rural locations were 1.9 times more likely than caregivers in urban locations to have more than a high school education (Wald $\left.\chi^{2}(2, N=3300)=34.11, p<0.000\right)$. However, Black caregivers in rural locations were significantly less likely to have more than a high school education $\left(\mathrm{OR}=0.62\right.$, Wald $\left.\chi^{2}(1, N=3300)=11.70, p<0.001\right)$.

Where interactions of race and location were not significant, differences in demographics based on the main effects of race and location were examined. Race/ethnicity differences were found in homes in which the caregiver had a partner, number of adults in the home, and employment. Regardless of location, only about $40 \%$ of Black families had two caregivers in the home compared to about $70 \%$ of families of other races/ethnicities (Wald $\left.\chi^{2}(2, N=3652)=84397, p<0.001\right)$. Black caregivers reported working more hours per week than other participants regardless of location $(\mathrm{F}(2,3372)=7.36, p<$ 0.001). For example, $58.4 \%$ of Black caregivers worked 21 or more hours a week compared to $44.5 \%$ for Hispanic caregivers and $45.6 \%$ for white caregivers. All families in large rural areas had fewer adults in the home than families in other locations $(\mathrm{F}(2,3365)=7.03, p<0.001)$. Among Hispanic families, the number of adults in the home varied with the smallest families living in large rural areas and those with the most household size in urban areas $(\mathrm{F}(2,3365)=12.15, p<0.001)$.

\subsection{Total FMI-ACE Score by Race/Ethnicity and Geographic Location}

One-third of children experienced no ACEs (33.3\%). However, most (66.6\%) of the children in our sample had experienced at least one adverse event, with $28.6 \%$ experiencing one, $19.5 \%$ experiencing two, $10.1 \%$ with three, $4.8 \%$ with four, and $3.7 \%$ experienced more than four. As seen in Table 2, the average FMI-ACE score was $1.38(\mathrm{SD}=1.42$, range $0-8)$. The FMI-ACEs Parenting score was 0.74 $(\mathrm{SD}=0.91)$ and the FMI-ACEs Family score was $0.63(\mathrm{SD}=0.81)$.

In preliminary analyses, we examined the bivariate association of ACE scores across the locations and race/ethnicity of participants. Bivariate ANOVA indicated that the total FMI-ACE score differed 
by location $(\mathrm{F}(2,3413)=33.69, p<0.001)$ with post hoc, Holm-Bonferroni -corrected tests indicating that urban and large rural areas had higher FMI-ACE scores $(\mathrm{M}=1.50, \mathrm{SD}=1.45, \mathrm{M}=1.47, \mathrm{SD}=1.33$, respectively) than small rural areas $(\mathrm{M}=1.05, \mathrm{SD}=1.30)$. This pattern is confirmed with an examination of the percent of children with four or more FMI-ACE by location: Urban 9.7\%, Large Rural $7.8 \%$ and Rural 5.7\%.

Similar ANOVA analysis found differences by race/ethnicity $(\mathrm{F}(2,3413)=49.60, p<0.001)$ with Black children having the highest FMI-ACE score $(\mathrm{M}=1.60, \mathrm{SD}=1.43)$ followed by white children $(\mathrm{M}=1.25, \mathrm{SD}=1.33)$ and Hispanic children $(\mathrm{M}=1.01, \mathrm{SD}=1.34)$. This pattern is confirmed with an examination of the percent of children with FMI-ACE score at or above 4 by race: Black $10.4 \%$, white $7.8 \%$ and Hispanic $5.5 \%$.

Next, we examined the hypothesis that the total FMI-ACE score differed by location and ethnicity (i.e., interaction) using multivariate analyses. Missing data ranged from $11 \%$ (e.g., the number of children in the home) to less than $1 \%$ (e.g., relationship of child to caregiver). An examination of missing data indicated that the use of listwise deletion would result in a significant loss of cases, thus SAS/FIML was used in multivariate models to estimate FMI-ACE scores. Based on this model, after controlling for family, child characteristics, the main effects of race/ethnicity, and location, we entered four interaction terms in the model. No interaction term was significant.

An examination of the main effects in the SAS/FIML multivariate model without interactions found similar results as the bivariate analyses for race/ethnicity with Black children having higher FMI-ACE scores than whites and Hispanic children having lower FMI-ACE scores than whites $(\mathrm{t}(1)$ $=2.12, p=0.04 ; \mathrm{t}(1)=-5.38, p<0.001)$. The Cohen's d effect size between the number of FMI-ACEs between Black and white children was moderate in size at 0.52 . Across geographic locations, differences were identified between children in rural areas. Based on this analysis, children in rural areas had lowest total FMI-ACE score but children from urban and large rural areas had similar FMI-ACE score $(t(1)=-3.31, p=0.00 ; t(1)=-0.33, p<0.74)$. The Cohen's d effect size between the number of FMI-ACEs between urban and rural children was smaller at 0.38 .

\subsection{FMI-ACEs Parenting and Family Sub-Scores}

For FMI-ACEs Parenting, our analyses indicated that race moderated the risk score across locations. That is, in urban and large rural areas, a consistent pattern of FMI-ACEs Parenting risk was seen with Black children at highest risk $(M=0.92, M=0.83)$, white children at moderate risk $(M=0.69$, $\mathrm{M}=0.72)$ and Hispanic children at lowest risk $(\mathrm{M}=0.56, \mathrm{M}=0.37)$. However, in rural areas, white children $(\mathrm{M}=0.61)$ were at the highest risk and Black children at lowest risk $(\mathrm{M}=0.46, \mathrm{t}(1)=-2.69$, $p<0.007)$. The Cohen's d effect size between the number of FMI-ACEs Parenting risks between urban and rural Black children was moderate at 0.62 . Hispanic children's risk was not statistically different across locations.

For FMI-ACEs Family, our analyses indicated two significant interactions with shifts between the three geographic locations. Children from white families $(\mathrm{M}=0.94,0.93,0.86$ for urban, large rural, small rural respectively) had relatively stable risk across location. Children from Black families living in large rural areas were more at risk than small rural areas $(\mathrm{M}=0.87,0.97,0.77$ for urban, large rural, rural respectively). The Cohen's d effect size between the number of FMI-ACEs Family risks between small rural and large rural Black children was smaller at 0.21 . However, children from Hispanic homes ( $\mathrm{M}=0.74,0.65,0.83$ for urban, large rural, small rural respectively) had significantly low risks in large rural areas compared to other children. For example, the effect size between white and Hispanic families living in large rural areas was 0.31 .

\section{Discussion}

Our study provided the first investigations of exposure to ACEs across geographic setting considering the potential for race/ethnicity to act as a moderator within the context of poverty [33]. In a range of studies, ACEs have been linked to long-term adult health and wellness. The concern for 
children in rural areas is twofold. First, the NSCH suggested that rural children are at greater risk for adverse experiences. Second, children and their families living in poverty within rural communities have unique challenges. Our intent was to expand on the findings of NSCH by examining ACEs using a definition more closely aligned with the Kaiser-ACEs definition in the context of poverty in the rural south.

Beyond the value of our study to examine the moderation of risk, the study is valuable as one of the few studies of geographic comparisons for ACEs in young children. In fact, the Family Map Inventories are one of few tools with widespread use targeting very young children [8]. There have been a few studies of ACEs in rural areas using the Centers for Disease Control and Prevention's (CDC) Behavioral Risk Factor Surveillance System (BRFSS) in adults [18]. A review of these results suggests that rural and urban adults reporting on past ACEs appear to have roughly the same levels of risk regardless of current residence [48]. However, the assessment of adult reports of childhood experiences at least 18 years ago is less helpful for targeting efforts to address and prevent ACEs for young children.

Findings from our study suggested that an examination of the total NSCH-ACE score does not provide an accurate summary of the risk exposure for low-income children and when comparing rural children to urban children. In the NSCH study, racial experiences were assessed with a question of experienced racial discrimination. We approached this differently, in part because the children in our study were young. Based on our analyses of the total FMI-ACE score, race was not a moderator of risk. However, contrary to the NSCH study, children living in rural areas were less often exposed to adverse events than children in urban areas regardless of race. Still, Black children experienced more FMI-ACEs than other children regardless of location.

We examined two sub-scores intended to assess the exposure of children to risks associated with parenting and family demographic risk factors separately. When the risks related to FMI-ACEs Parenting were examined, the level of risk across geographic locations for adverse childhood experiences depended on race. That is, an examination of the number of FMI-ACEs Parenting score suggested that urban areas were associated with more risk (e.g., 0.81 urban vs 0.55 rural risks). For example, children from Black families were at higher risk in more populated areas but at less risk for parenting-related risks associated with child maltreatment in rural areas. However, the risk is relatively level for white and Hispanic families, which have less risk in large rural areas compared to urban areas. The reduction of risk in rural areas for Black and Hispanic families compared to urban areas was such that white children had the highest risk in rural areas.

Overall, results from FMI-ACEs Family risks were similar to FMI-ACEs Parenting in that rural areas present less risk to children than urban areas for many children. This subscale is somewhat similar to the one used in the NSCH study. However, the studies differed in where children most at risk lived. In the NSCH study, rural children were more at risk than urban children. In our study, risk was dependent on the geographic location of the child. That is, for the FMI-ACEs Family scale, Hispanic children living in large rural areas had more risks than rural Hispanic children; but the situation was reversed for Black children. Black children in rural areas had the fewest risks and black children in large rural areas the most. This finding may be a function of the difference in the way each study treated racial influences. In our study we compared the risks by racial groups whereas the NSCH study included the experiences of racial discrimination as part of the risk experienced.

One limitation, but also potential strength, of our study is the economic homogeneity of the study population, since all of the children were from low-income families. The ACE prevalence found in our study participants is likely to be higher than the general population, as children living in poverty are more susceptible to ACE exposure [19]. Future research should replicate our study in a more economically diverse population to determine if the patterns of specific ACE exposure remain consistent across varying socioeconomic statuses. However, our focus on children from low-income families is also a strength as it guides our understanding of the children who are at highest risk of ACEs and their negative consequences, allowing for the development of more precise and effective interventions for the children who need it most. 
Another strength of the study is examining ACEs using the FMI. The FMI-ACEs represent proxies for ACEs (e.g., asking if the parent spanks with objects, rather than asking about confirmed physical abuse) that are measured within a specific period. This is particularly relevant as asking parents directly about ACEs could be potentially incriminating (e.g., ACEs represent stigmatized and potentially illegal activities), making them likely unreliable. Further, the FMI-ACEs screening provides an avenue for clinicians and interventionists to identify risks while maintaining a working relationship with parents, whose engagement and eventual behavior modification are critical for reducing the identified risks.

\section{Conclusions}

Overall, this study provides a new perspective on ACEs and the children who experience them by examining ACE exposure in terms of both geography and race. Retrospective studies of adults, while helpful, are not as useful in directing resources and intervention efforts as studies of the current experiences of children. By taking into account urban versus rural environment and white versus minority status, we were able to examine each group's risk factors pertaining to parenting and their home environment. Our study provided strong evidence that individual ACEs are not experienced equally across racial and geographic divides. This information has public health implications, as it is critical to know which children are most at risk for specific ACEs in order to implement proper screening. As we learn more about ACE exposure and its consequences, the need for ACE screening in pediatric clinics has become apparent. More work is needed to establish the feasibility and acceptability of screening for these sensitive topics in the clinical setting; however, there is already some evidence showing that ACE assessment can be viewed positively by parents [49]. Furthermore, the next step after screening is to develop interventions that are culturally appropriate and can be practically implemented to assist families in ameliorating their unique risk factors. Currently, there is evidence to support interventions such as parenting education programs and mental health treatment. It would be beneficial to identify in future work when interventions are equally effective across racial and geographical differences [50-52].

Author Contributions: Conceptualization, L.W.-M. and L.M.; Methodology, L.W.-M., L.M., and J.P.S.; Software, L.W.-M., and J.P.S.; Formal Analysis, L.W.-M. and J.P.S.; Investigation, L.W.-M., L.M.; Data Curation, L.W.-M., L.M.; Writing-Original Draft Preparation, L.W.-M., L.M.; Writing-Review \& Editing, J.S.; Project Administration, L.W.-M.

Funding: Funding for this study was made possible in part by the Health Resources and Services Administration (HRSA) of the U.S. Department of Health and Human Services (HHS) under grant number D89MC23141 of the Affordable Care Act-Maternal, Infant, and Early Childhood Home Visiting Program awarded to the Arkansas Department of Health. This study was also funded in part by the HHS Office of Head Start (90YD0254) and Administration on Children, Youth, \& Families (90YF0051). The information or content and conclusions expressed in this material or by speakers and moderators are those of the author(s) and should not be construed as the official position or policy of, nor should any endorsements be inferred by HRSA, HHS, or the U.S. Government.

Conflicts of Interest: Leanne Whiteside-Mansell, Taren Swindle, and UAMS have a financial interest in the technology discussed in this publication. These financial interests have been reviewed and approved in accordance with the UAMS conflict of interest policies.

\section{References}

1. Kim, K.; Ozegovic, D.; Voaklander, D.C. Differences in incidence of injury between rural and urban children in Canada and the USA: A systematic review. Inj. Prev. 2012, 18, 264-271. [CrossRef] [PubMed]

2. Health Resources and Services Administration. The Health and Well-Being of Children in Rural Areas: A Portrait of the Nation 2011-2012; U.S. Department of Health and Human Services: Rockville, Maryland, 2015; p. 51.

3. The 2009 Report to the Secretary: Rural Health and Human Services Issues. Available online: https: //www.hrsa.gov/advisorycommittees/rural/2009secreport.pdf (accessed on 22 July 2019).

4. Farrigan, T. Rural Poverty \& Well-Being. Available online: https://www.ers.usda.gov/topics/rural-economypopulation/rural-poverty-well-being/ (accessed on 22 July 2019). 
5. US Census Bureau American Community Survey: New Census Data Show Differences Between Urban and Rural Populations. Available online: https://www.census.gov/newsroom/press-releases/2016/cb16-210.html (accessed on 22 July 2019).

6. Grace, C.; Zaslow, M.; Brown, B.; Aufseeser, D.; Bell, L. Rural Disparities in Baseline Data of the Early Childhood Longitudinal Study. Available online: http://www.ruraledu.org/user_uploads/file/ EarlyChildhood.pdf\#page $=24$ (accessed on 22 July 2019).

7. Choo, E.K.; Spiro, D.M.; Lowe, R.A.; Newgard, C.D.; Hall, M.K.; McConnell, K.J. Rural-urban disparities in child abuse management resources in the emergency department. J. Rural Health 2010, 26, 361-365. [CrossRef] [PubMed]

8. Bethell, C.D.; Carle, A.; Hudziak, J.; Gombojav, N.; Powers, K.; Wade, R.; Braveman, P. Methods to Assess Adverse Childhood Experiences of Children and Families: Toward Approaches to Promote Child Well-being in Policy and Practice. Acad. Pediatr. 2017, 17, S51-S69. [CrossRef] [PubMed]

9. Felitti, V.J.; Anda, R.F.; Nordenberg, D.; Williamson, D.F.; Spitz, A.M.; Edwards, V.; Koss, M.P.; Marks, J.S. Relationship of Childhood Abuse and Household Dysfunction to Many of the Leading Causes of Death in Adults. Am. J. Prev. Med. 1998, 14, 245-258. [CrossRef]

10. SAMHSA Adverse Childhood Experiences. Available online: https://www.integration.samhsa.gov/clinicalpractice/trauma (accessed on 22 July 2019).

11. McKelvey, L.M.; Saccente, J.E.; Swindle, T.M. Adverse Childhood Experiences in Infancy and Toddlerhood Predict Obesity and Health Outcomes in Middle Childhood. Child. Obes. 2019, 15, 206-215. [CrossRef] [PubMed]

12. McKelvey, L.M.; Edge, N.C.; Mesman, G.R.; Whiteside-Mansell, L.; Bradley, R.H. Adverse experiences in infancy and toddlerhood: Relations to adaptive behavior and academic status in middle childhood. Child. Abus. Negl. 2018, 82, 168-177. [CrossRef] [PubMed]

13. McKelvey, L.M.; Edge, N.A.C.; Fitzgerald, S.; Kraleti, S.; Whiteside-Mansell, L. Adverse childhood experiences: Screening and health in children from birth to age 5. Fam. Syst. Health 2017, 35, 420-429. [CrossRef] [PubMed]

14. McKelvey, L.M.; Selig, J.P.; Whiteside-Mansell, L. Foundations for screening adverse childhood experiences: Exploring patterns of exposure through infancy and toddlerhood. Child. Abus. Negl. 2017, 70, 112-121. [CrossRef]

15. Mckelvey, L.M.; Whiteside-Mansell, L.; Conners-Burrow, N.A.; Swindle, T.M.; Fitzgerald, S. Assessing adverse experiences from infancy through early childhood in home visiting programs. Child. Abus. Negl. 2016, 51, 295-302. [CrossRef]

16. Brown, M.J.; Thacker, L.R.; Cohen, S.A. Association between adverse childhood experiences and diagnosis of cancer. PLoS ONE 2013, 8, e65524. [CrossRef]

17. Anda, R.F.; Brown, D.W.; Dube, S.R.; Bremner, J.D.; Felitti, V.J.; Giles, W.H. Adverse Childhood Experiences and Chronic Obstructive Pulmonary Disease in Adults. Am. J. Prev. Med. 2008, 34, 396-403. [CrossRef] [PubMed]

18. National Center for Injury Prevention and Control. Violence Prevention-Behavioral Risk Factor Surveillance System ACE Data. Available online: https://www.cdc.gov/violenceprevention/childabuseandneglect/ acestudy/ace-brfss.html (accessed on 22 July 2019).

19. American Academy of Pediatrics Adverse Childhood Experiences and the Lifelong Consequences of Trauma. Available online: https://www.aap.org/en-us/Documents/ttb_aces_consequences.pdf (accessed on 5 August 2016).

20. Bethell, C.D.; Davis, M.B.; Gombojav, N.; Stumbo, S.; Powers, K. Issue Brief: A National and Across State Profile on Adverse Childhood Experiences among Children and Possibilities to Heal and Thrive. Available online: https:/www.acesconnection.com/fileSendAction/fcType/0/fcOid/471939070121860415/filePointer/ 471939070121860437/fodoid/471939070121860432/aces_brief_final\%20US\%20Children.pdf. (accessed on 22 July 2019).

21. Sacks, V.; Murphey, D. The prevalence of Adverse Childhood Experiences, Nationally, by State, and by Race or Ethnicity; Child Trends: Bethesda, MD, USA, 2018.

22. Chiu, G.R.; Lutfey, K.E.; Litman, H.J.; Link, C.L.; Hall, S.A.; Mckinlay, J.B. Prevalence and Overlap of Childhood and Adult Physical, Sexual, and Emotional Abuse: A Descriptive Analysis of Results from the Boston Area Community Health (BACH) Survey. Violence Vict. 2013, 28, 381-402. [CrossRef] [PubMed] 
23. Radcliff, E.; Crouch, E.; Strompolis, M. Rural-urban differences in exposure to adverse childhood experiences among South Carolina adults. Rural Remote Health 2018, 18, 4434. [CrossRef] [PubMed]

24. Kim, H.S. Consequences of parental divorce for child development. Am. Sociol. Rev. 2011, 76, 487-511. [CrossRef]

25. Slopen, N.; Shonkoff, J.P.; Albert, M.A.; Yoshikawa, H.; Jacobs, A.; Stoltz, R.; Williams, D.R. Racial Disparities in Child Adversity in the U.S.: Interactions with Family Immigration History and Income. Am. J. Prev. Med. 2016, 50, 47-56. [CrossRef] [PubMed]

26. Murphey, D.; Cooper, P.M. Parents Behind Bars: What Happens to Their Children? Child. Trends: Bethesda, MD, USA, 2015; pp. 1-20.

27. Peek-Asa, C.; Wallis, A.; Harland, K.; Beyer, K.; Dickey, P.; Saftlas, A. Rural Disparity in Domestic Violence Prevalence and Access to Resources. J. Women's Heal. 2011, 20, 1743-1749. [CrossRef]

28. Intimate Partner Violence in Rural America. Available online: https:/www.hrsa.gov/advisorycommittees/ rural/publications/partnerviolencemarch2015.pdf (accessed on 22 July 2019).

29. Van Gundy, K. Substance Abuse in Rural and Small Town America; Carsey Institute, University of New Hampshire: Durham, NH, USA, 2006.

30. Gruebner, O.; Rapp, M.A.; Adli, M.; Kluge, U.; Galea, S.; Heinz, A. Cities and Mental Health. Dtsch. Arztebl. Int. 2017, 114, 121. [CrossRef]

31. Anda, R.F.; Felitti, V.J.; Bremner, J.D.; Walker, J.D.; Whitfield, C.; Perry, B.D.; Dube, S.R.; Giles, W.H. The Enduring Effects of Abuse and Related Adverse Experiences in Childhood: A Convergence of Evidence from Neurobiology and Epidemiology. Eur. Arch. Psychiatry Clin. Neurosci. 2006, 256, 174-186. [CrossRef]

32. Chanlongbutra, A.; Singh, G.K.; Mueller, C.D. Adverse Childhood Experiences, Health-Related Quality of Life, and Chronic Disease Risks in Rural Areas of the United States. J. Environ. Public Health 2018, 2018, 1-15. [CrossRef]

33. Exploring the Rural Context for Adverse Childhood Experiences (ACEs). Available online: https://www.hrsa.gov/sites/default/files/hrsa/advisory-committees/rural/publications/Rural-Contextfor-ACEs-August2018.pdf (accessed on 22 July 2019).

34. Whiteside-Mansell, L.; Bradley, R.; Conners, N.; Bokony, P. The Family Map: Structured family interview to identify risks and strengths in Head Start families. NHSA Dialog 2007, 10, 189-209. [CrossRef]

35. Head Start Eclkc. Poverty Guidelines and Determining Eligibility for Participation in Head Start Programs. Available online: https:/eclkc.ohs.acf.hhs.gov/eligibility-ersea/article/poverty-guidelines-determiningeligibility-participation-head-start (accessed on 22 July 2019).

36. Arkansas Better Chance Program Manual. Available online: https:/humanservices.arkansas.gov/images/ uploads/dccece/ABC\%20Program\%20Manual.pdf (accessed on 22 July 2019).

37. Whiteside-Mansell, L.; Johnson, D.; Bokony, P.; McKelvey, L.; Burrow, N.; Swindle, T. Using the Family Map: Supporting Family Engagement with Parents of Infants and Toddlers. Special Issue on Parent Involvement and Engagement in Head Start for Dialog. Available online: https://journals.uncc.edu/dialog/article/view/42/100 (accessed on 22 July 2019).

38. Parker, T. Rural-Urban Continuum Codes. Available online: https://www.ers.usda.gov/data-products/ruralurban-continuum-codes/ (accessed on 22 July 2019).

39. Vogel, C.A.; Caronongan, P.; Thomas, J.; Bandel, E. Toddlers in Early Head Start: A Portrait of 2-Year-Olds, Their Families, and the Programs Serving Them (Executive Summary); U.S. Department of Health \& Human Services: Washington, DC, USA, 2015.

40. U.S. Department of Health and Human Services. A Descriptive Study of Head Start Families: FACES Technical Report I; U.S. Department of Health and Human Services: Washington, DC, USA, 2002.

41. Mersky, J.P.; Janczewski, C.E.; Topitzes, J. Rethinking the Measurement of Adversity: Moving Toward Second-Generation Research on Adverse Childhood Experiences. Child. Maltreat. 2017, 22, 58-68. [CrossRef] [PubMed]

42. Shaffer, J.P. Multiple Hypothesis Testing. Annu. Rev. Psychol. 1995, 46, 561-584. [CrossRef]

43. Holm, S. Board of the Foundation of the Scandinavian Journal of Statistics A Simple Sequentially Rejective Multiple Test. Procedure A Simple Sequentially Rejective Multiple Test Procedure; University of Kassel: Kassel, Germany, 1979; Volume 6 
44. Yung, Y.-F.; Zhang, W. Making Use of Incomplete Observations in the Analysis of Structural Equation Models: The CALIS Procedure's Full Information Maximum Likelihood Method in SAS/STAT ${ }^{\circledR}$ 9.3. In Proceedings of the SAS Global Forum 2011, Las Vegas, NV, USA, 4-7 April 2011; SAS Institute Inc.: Cary, NC, USA, 2011.

45. Allison, P.D. Handling Missing Data by Maximum Likelihood. Available online: http://www. statisticalhorizons.com/wp-content/uploads/MissingDataByML.pdf (accessed on 14 June 2019).

46. Enders, C.K. The Performance of the Full Information Maximum Likelihood Estimator in Multiple Regression Models with Missing Data. Educ. Psychol. Meas. 2001, 61, 713-740. [CrossRef]

47. Pasta, D.J. Those Confounded Interactions: Building and Interpreting a Model with Many Potential Confounders and Interactions. In Proceedings of the SAS Global Forum 2011, Las Vegas, NV, USA, 4-7 April 2011; SAS Institute Inc.: Cary, NC, USA, 2011.

48. National Advisory Committee on Rural Health and Human Services. Exploring the rural context for adverse childhood experiences (ACEs). Department of Health and Human Services, 2018. Available online: https://www.hrsa.gov/sites/default/files/hrsa/advisory-committees/rural/publications/Rural-Contextfor-ACEs-August2018.pdf (accessed on 5 July 2019).

49. Conn, A.-M.; Szilagyi, M.A.; Jee, S.H.; Manly, J.T.; Briggs, R.; Szilagyi, P.G. Parental perspectives of screening for adverse childhood experiences in pediatric primary care. Fam. Syst. Heal. 2018, 36, 62-72. [CrossRef] [PubMed]

50. Marie-Mitchell, A.; Studer, K.R.; O'Connor, T.G. How knowledge of adverse childhood experiences can help pediatricians prevent mental health problems. Fam. Syst. Health 2016, 34, 128-135. [CrossRef] [PubMed]

51. Borowsky, I.W. Effects of a Primary Care-Based Intervention on Violent Behavior and Injury in Children. Pediatrics 2004, 114, e392-e399. [CrossRef] [PubMed]

52. Duggan, A.; McFarlane, E.; Fuddy, L.; Burrell, L.; Higman, S.M.; Windham, A.; Sia, C. Randomized trial of a statewide home visiting program: Impact in preventing child abuse and neglect. Child. Abuse Negl. 2004, 28, 597-622. [CrossRef]

(C) 2019 by the authors. Licensee MDPI, Basel, Switzerland. This article is an open access article distributed under the terms and conditions of the Creative Commons Attribution (CC BY) license (http://creativecommons.org/licenses/by/4.0/). 